\title{
Redundant nerve roots of the cauda equina: review of the literature*
}

\author{
Raízes nervosas redundantes da cauda equina: revisão da literatura \\ Marcello Henrique Nogueira-Barbosa ${ }^{1}$, Leonor Garbin Savarese ${ }^{2}$, Carlos Fernando Pereira \\ da Silva Herrero ${ }^{3}$, Helton Luiz Aparecido Defino ${ }^{4}$
}

\begin{abstract}
In imaging diagnosis, redundant nerve roots of the cauda equina are characterized by the presence of elongated, enlarged and tortuous nerve roots in close relationship with a high-grade lumbar spinal canal stenosis. This is not an independent entity, but it is believed to be a consequence of the chronic compression at the level of the lumbar canal stenosis and thus may be part of the natural history of lumbar spinal stenosis. The present paper is aimed at reviewing the histopathological, electrophysiological and imaging findings, particularly at magnetic resonance imaging, as well as the clinical meaning of this entity. As the current assessment of canal stenosis and root compression is preferably performed by means of magnetic resonance imaging, this is the imaging method by which the condition is identified. The recognition of redundant nerve roots at magnetic resonance imaging is important, particularly to avoid misdiagnosing other conditions such as intradural arteriovenous malformations. The literature approaching the clinical relevance of the presence of redundant nerve roots is controversial. There are articles suggesting that the pathological changes of the nerve roots are irreversible at the moment of diagnosis and therefore neurological symptoms are less likely to improve with surgical decompression, but such concept is not a consensus.
\end{abstract}

Keywords: Cauda equina; Spinal stenosis; Spine; Magnetic resonance imaging.

Resumo A redundância das raízes nervosas da cauda equina é caracterizada, no diagnóstico por imagem, pela presença de raízes nervosas alongadas, espessadas e tortuosas junto a uma área de estenose do canal vertebral lombar. Não é uma entidade independente, mas acredita-se que ocorra como o resultado da compressão crônica ao nível da estenose do canal lombar e que, portanto, pode fazer parte da evolução natural da estenose. O objetivo deste trabalho é revisar a histopatologia, a eletrofisiologia, as características de imagem, especialmente na ressonância magnética, e o significado clínico desta entidade. Como a avaliação atual da estenose de canal e das compressões radiculares é realizada preferencialmente por meio da ressonância magnética, é nesse método de imagem que a redundância das raízes nervosas da cauda equina será identificada. O reconhecimento desta entidade nos exames de ressonância magnética é importante, principalmente para evitar equívocos que poderiam levar ao diagnóstico de outras afecções, particularmente de malformações arteriovenosas intradurais. A literatura é controversa a respeito da importância clínica da presença de redundância das raízes nervosas da cauda equina. Há artigos que sugerem que as alterações patológicas da raiz nervosa são irreversíveis no momento do diagnóstico e que os sintomas neurológicos não são mais suscetíveis de melhora com a descompressão cirúrgica, porém este conceito não é um consenso.

Unitermos: Cauda equina; Estenose espinhal; Coluna vertebral; Ressonância magnética.

Nogueira-Barbosa MH, Savarese LG, Herrero CFPS, Defino HLA. Redundant nerve roots of the cauda equina: review of the literature. Radiol Bras. 2012 Mai/Jun;45(3):155-159.

\footnotetext{
* Study developed at the Service of Radiodiagnosis of Centro de Ciências das Imagens e Física Médica (CCIFM), Hospital das Clínicas da Faculdade de Medicina de Ribeirão Preto da Universidade de São Paulo (HC-FMRPUSP), Ribeirão Preto, SP, Brazil.

1. PhD, Professor at Centro de Ciências das Imagens e Física Médica (CCIFM), Faculdade de Medicina de Ribeirão Preto da Universidade de São Paulo (FMRPUSP), Ribeirão Preto, SP, Brazil.

2. Graduate Student of Medicine, Faculdade de Medicina de Ribeirão Preto da Universidade de São Paulo (FMRPUSP), Ribeirão Preto, SP, Brazil.

3. Master, MD, Physician Assistant at the Spine Surgery Section, Division of Orthopedics, Hospital das Clínicas da Faculdade de Medicina de Ribeirão Preto da Universidade de São Paulo (HC FMRPUSP), Ribeirão Preto, SP, Brazil.

4. PhD, Professor, Department of Biomechanics, Medicine and Rehabilitation of the Locomotor System at Faculdade de Medicina de Ribeirão Preto da Universidade de São Paulo (FMRPUSP), Ribeirão Preto, SP, Brazil.
}

\section{INTRODUCTION}

Redundant nerve roots (RNR) of the cauda equina is characterized by the presence of elongated, enlarged and tortuous nerve roots in the subarachnoid space of the lumbar column adjacent to a site of canal

Mailing Address: Leonor Garbin Savarese. Faculdade de Medicina de Ribeirão Preto - Universidade de São Paulo. Avenida Bandeirantes, 3900, Campus Universitário. Ribeirão Preto, SP, Brazil, 14049-090. E-mail: leonorgs@usp.br

Received May 28, 2011. Accepted after revision February 24, 2012. stenosis $^{(\mathbf{1 - 1 1})}$. Initially, RNR of the cauda equina was described as being identified at myelography as serpiginous filling defects associated with partial or total blockage preventing the transit of contrast material $^{(1-9)}$. Most recently imaging findings of RNR of the cauda equina were also described for magnetic resonance imaging $(\mathrm{MRI})^{(\mathbf{1 0 - 1 2})}$. The prevalence of this syndrome may reach $33.8-42 \%$ of patients with lumbar canal stenosis ${ }^{(8,10,13)}$ and has been detected in $8.2 \%$ of elderly cadavers in $\operatorname{Japan}^{(8)}$. 
Some studies attribute the first description of RNR of the cauda equina to Verbiest $^{(\mathbf{1 1 - 1 3 )}}$. Such studies specifically mention an article where Verbiest has described a series of surgically confirmed cases of lumbar spinal stenosis ${ }^{(\mathbf{1 4})}$ but, as the original text was evaluated, the authors of the present review concluded that Verbiest described elongated nerve roots in another series of cases about rare presentations of cauda equina compression ${ }^{(\mathbf{1 5})}$. However, the term "RNR of the cauda equina" was first utilized by Cressman \& Pawl ${ }^{(\mathbf{1})}$.

The literature is controversial on the clinical relevance of the presence of redundant roots of the cauda equina. There are articles suggesting that the degenerative pathological changes in the affected nerve roots are irreversible and, therefore, the neurological symptoms would be less likely to improve with surgical decompression, but consensus is still to be reached on such concept.

Redundancy of the nerve roots is probably the pathological result of a chronic compressive force at the level of the site of spinal canal constriction ${ }^{(\mathbf{9})}$.

The present article is aimed at reviewing the findings described on publications related to RNR of the cauda equina, with emphasis on imaging findings, and particularly at MRI. Additionally, studies on the clinical significance of this entity were reviewed.

\section{HISTOPATHOLOGICAL STUDY}

Suzuki et al. have analyzed clinical aspects, radiological studies and electrophysiology studies of patients with and without RNR of the cauda equina and investigated anatomical and histopathological findings of redundant and non-redundant nerve roots in cadavers ${ }^{(\mathbf{8 , 9})}$. The main pathological findings in patients with RNR of the cauda equina were derangement and reduction in the number of nervous fibers, demyelination, besides endoneural fibrosis and Schwann cells proliferation ${ }^{(\mathbf{8 , 9})}$. In their investigation, those authors have not demonstrated any significant change in the anterior horn and in the anterolateral columns of the spinal cord. Low degree of nerve cells loss and spinal ganglion fibrosis were observed, but such changes were equally present in non-redundant roots and were, therefore, considered as changes related to aging.

The topographic distribution in observed in cases of redundant nerve roots was $33.3 \%$ in $\mathrm{S} 1,33.3 \%$ at $\mathrm{S} 2,16 \%$ at L5 and $17.3 \%$ below the $\mathrm{S} 2$ roots $^{(\mathbf{8})}$. The anatomical study developed by Suzuki et al. has demonstrated that all redundant nerve roots pass through the spinal canal constriction. No redundancy was observed in roots which did not pass by the site of canal constriction $^{(\mathbf{8})}$. Demyelination and axonal loss was considered as being a consequence of the continuous mechanical compression of nerve roots confined to the stenosed spinal canal $^{(8)}$.

\section{ELECTROPHYSIOLOGY}

The electrophysiological study of redundant nerve roots has demonstrated temporal dispersion of the action potential and delay of the velocity of the sensitive nervous conduction, although the difference in the velocity of sensitive nervous conduction has not been statistically significant ${ }^{(\mathbf{8})}$. The study authors have suggested that such results reflected the reduction and degeneration of the nerve fibers ${ }^{(\mathbf{8})}$. They also have not found any significant difference in the electrophysiological manifestation between ventral and dorsal redundant nerve roots.

Measurements of the redundant and non-redundant nerve roots conduction velocity were performed during surgery ${ }^{(\mathbf{1 3})}$. In that study, the velocity of conduction of redundant nerve roots was approximately one half the normal value and, in general, the redundant nerve roots presented multiphase action potentials temporarily dispersed as compared with the normal roots.

Only one case report approached the evaluation of electromyographic changes related to RNR of the cauda equina in the postoperative period ${ }^{(\mathbf{1 6})}$. Such report has documented preoperative partial denervation of the left medial segment of the gastrocnemius muscle and, in spite of the significant pain relief experienced by the patient after laminectomy, electromyographic changes in the gastrocnemius muscle were still present over the three-month and sixmonth follow-up.

\section{INTRAOPERATIVE FINDINGS}

Several authors have described cases of elongated and tortuous nerve roots after opening the dura mater, confirming the preoperative imaging findings ${ }^{(\mathbf{1 , 2}, \mathbf{4}-\mathbf{6}, \mathbf{1 1}, \mathbf{1 3})}$. Spontaneous extrusion of elongated roots usually occurs during the surgical opening of the dura mater ${ }^{(2,6,7,11,13)}$. The opening of the dura mater may be performed to rule out the hypothesis of arteriovenous malformation $^{(7)}$ or simply because surgeons have decided that such a procedure should be a part of the decompression ${ }^{(6,13)}$. Also, there are reports on the indication of duroplasty in association with decompressive laminectomy was indicated for the relief of nerve root compression ${ }^{(11,13)}$.

\section{MYELOGRAPHY}

In the literature, the diagnosis of RNR of the cauda equina was first described in studies approaching myelographic images $^{(\mathbf{1 - 9})}$. At the time, myelography was the only imaging method available to document the anatomy and pathology of nerve roots of the cauda equina in vivo. Currently, myelography has been widely replaced by MRI and its utilization has remained restricted to the rare cases where MRI is contraindicated or for those cases where postoperative metal artifacts are enough to severely degrade MRI images.

The myelographic pattern described in redundant nerve roots of the cauda equina corresponds to serpiginous intradural filling defects associated with a partial or complete blockage of the transit of contrast material and, therefore, spinal canal stenosis $^{(1-7)}$. Variations in the positioning of the patients may influence the presentation of RNR of the cauda equina at the images. The orthostatic position yields a better visualization of redundant roots ${ }^{(1,7,8,10)}$

Serpiginous filling defects may also be identified by myelography in the presence of dural or intradural arteriovenous malformations ${ }^{(\mathbf{1 7})}$, thus constituting an important differential diagnosis. Less frequently, a plexiform neurofibroma or a neurinoma may cause thickening and redundancy of nerve roots ${ }^{(\mathbf{1 8 - 2 0 )}}$. Other diseases can cause hypertrophic neuropathy such as arachnoiditis, chronic inflammatory demyelinat- 
ing polyneuropathy and some hereditary neuropathies; but association between such entities and serpiginous nerve roots of cauda equina was not reported.

\section{MAGNETIC RESONANCE IMAGING}

The characteristics of RNR of the cauda equina at MRI images have already been described by different authors ${ }^{(\mathbf{1 0 - 1 2})}$. Thickened, elongated and tortuous or serpiginous nerve roots adjacent to a site of lumbar vertebral canal stenosis represent typical findings. In the literature, signal intensity abnormalities nerve roots have not been reported in association with RNR of the cauda equina. Figures 1 and 2 illustrate the typical MRI findings in cases of redundant nerve roots.

At MRI, the main differential diagnosis must be done with dural arteriovenous malformations or arteriovenous fistulas. In such conditions, MRI usually shows intradural serpiginous vessels and ectasia of the coronal venous plexus (Figure 3). However, the clinical presentation of vascular

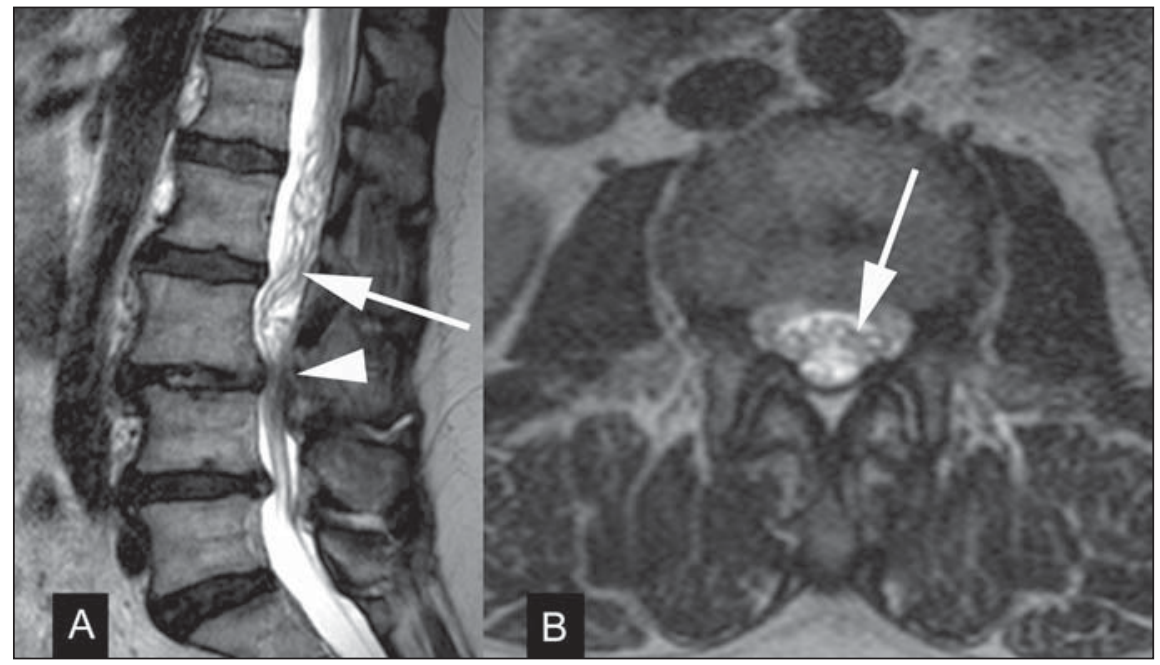

Figure 1. A 61-year-old woman with neurogenic claudication. Preoperative MRI images obtained for planning of surgical decompression. A: Sagittal MRI T2-weighted image demonstrates degenerative changes of the spine with disc herniation and vertebral canal stenosis at L3-4 and L4-5 levels (arrowhead). Elongated and tortuous nerve roots of the cauda equina can be identified (arrow). B: Axial MRI T2-weighted image obtained at a level slightly above the L3-4 stenosis, also presenting tortuous nerve roots (arrow). malformations is different from that of canal stenosis, and there are MRI findings that help in the differentiation between these two conditions. RNR are typically associated with vertebral canal stenosis, and clinically the patient presents neurogenic claudication. At the images, arteriovenous malformations are frequently associated with great draining vessels, and may

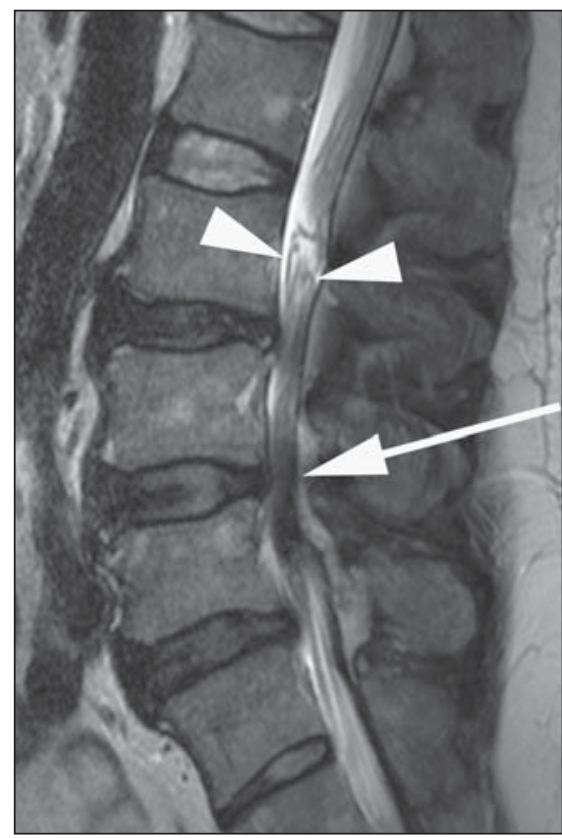

Figure 2. A 53-year-old man with clinical manifestations of neurogenic claudication. Sagittal MRI T2weighted image demonstrates severe lumbar spinal canal stenosis (arrow) and redundant nerve roots of the cauda equina roots (arrowheads).
Figure 3. Surgically confirmed spinal arteriovenous fistula. A,B: Sagittal MRI T2-weighted image showing dilated serpiginous vessels (arrow). Presence of increased signal intensity in the spinal cord substance (arrowhead) associated with medullary ischemia secondary to steal phenomenon. C: Coronal MRI T2-weighted image also demonstrating dilated serpiginous vessels in the venous plexus (arrow).

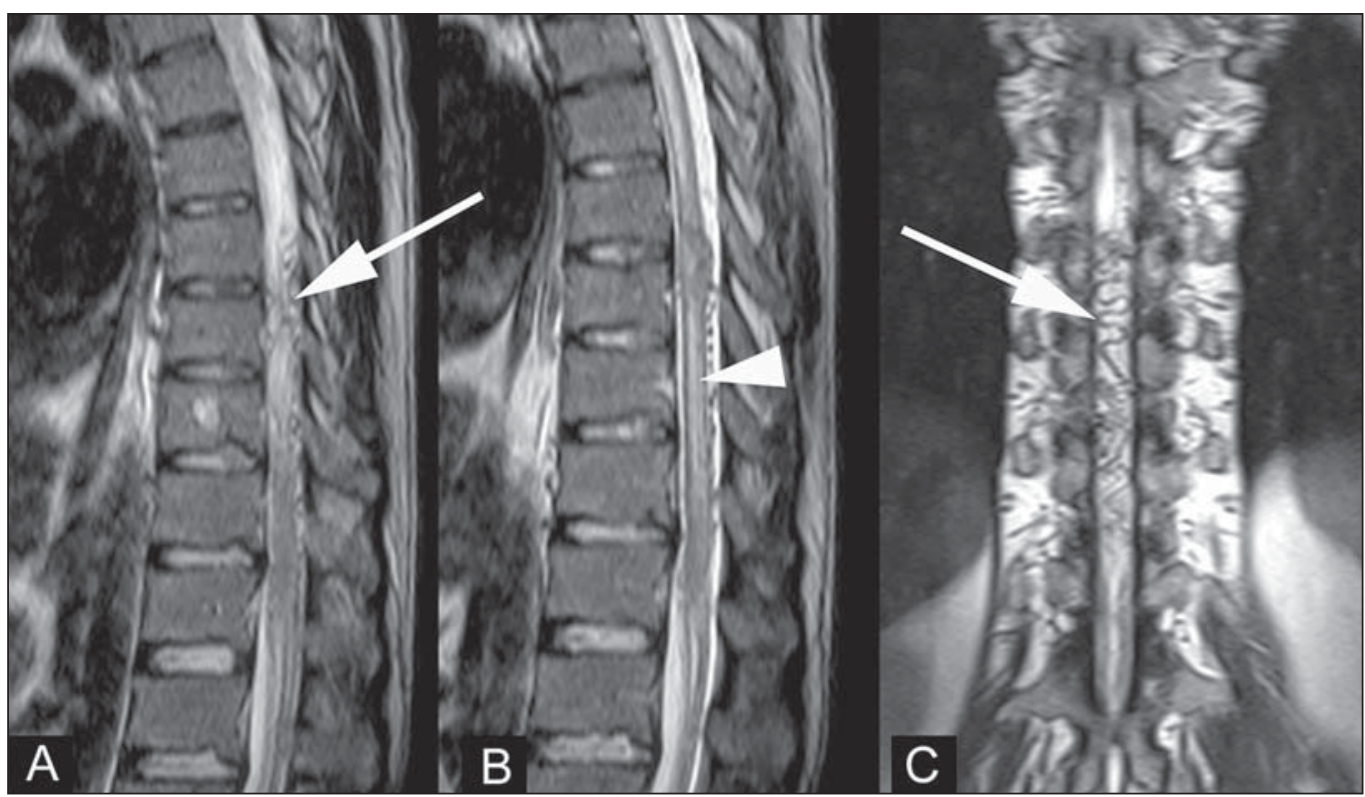


clinically present with signs of myelopathy, subarachnoid hemorrhage or medullary ischemia $^{(7,17)}$. Dural arteriovenous fistula is usually associated with abnormalities in signal intensity of the spinal cord on MRI T2-weighted sequences ${ }^{(\mathbf{1 7})}$. Another important imaging finding in the diagnosis of arteriovenous fistula is the exaggerated enhancement of the coronal venous plexus after gadolinium injection in $88 \%$ of the patients with such condition ${ }^{(17)}$.

Ono et al. have selected 44 patients with L4-5 spondylolisthesis submitted to detailed pre- and postoperative clinical evaluation, all of them presenting vertebral canal stenosis and complete blockage of the contrast material transit at preoperative myelography ${ }^{(\mathbf{1 0})}$. All the patients in that study were preoperatively submitted to myelography and MRI, and for the purpose of statistical analysis, the patients were divided into three groups, as follows: group A, patients with RNR of the cauda equina found both at myelography and MRI (16 patients); group B, patients with RNR of the cauda equina found only at myelography (14 patients); and group C, where none of the two studies demonstrated RNR of the cauda equina (14 patients). Statistically significant difference in relation to clinical symptoms was found between groups A and $\mathrm{C}$. The patients group where MRI demonstrated RNR of the cauda equina (group A) presented more severe clinical symptoms than group $\mathrm{C}$, both pre- and postoperatively. Ono et al. have identified that the group of patients in whom MRI could demonstrate RNR of the cauda equina presented worse clinical symptoms and, therefore, the identification of such finding by MRI would tend to have clinical significance $^{(\mathbf{1 0})}$. Then, the same authors speculated that the redundancy would have been underestimated at MRI in the less severe cases, where the redundancy was only demonstrated at myelography, probably because of the fact that, at MRI, the lumbar spine image acquisition is routinely performed with the patient in a neutral positioning, while the myelography study was performed with dynamic evaluation in the orthostatic position.

In another study, the relative length of the redundant nerve roots was measured on sagittal MR images and presented statisti- cal relationship with clinical improvement within the group of patients with $\mathrm{RNR}^{(\mathbf{1 2})}$. The authors standardized the measurement of the relative length of the nerve roots on the most central sagittal image of the lumbar column. The relative length was obtained by measuring the distance from the maximum stenosis level to the most distant point where the presence of redundant roots could be identified, and by dividing such obtained value by the height of the vertebral body located above the stenosis level. The greater the relative length, the better the postoperative outcomes, a result that, at a first analysis, seems to be unexpected, leading the study authors to raise the hypothesis that such result was related to a greater accommodation capability of the longer redundant roots during flexion and extension of the spinal column, as related to effects of traction forces ${ }^{(\mathbf{1 2})}$. The present study authors did not find any other study investigating such type of imaging finding in relation to postsurgical outcomes.

\section{DISCUSSION}

RNR of the cauda equina is a relatively common MRI finding in the lumbar vertebral column in cases where canal stenosis is present. The clinical condition of patients with RNR of the cauda equina is related to the natural history of the lumbar spinal canal stenosis. One believes that chronic lumbar stenosis is the primary cause of symptoms. The results from the study developed by Suzuki et al. suggest that patients with RNR of the cauda equina present more advanced ages, longer symptoms duration and greater severity of neurological signs and symptoms than patients presenting canal stenosis without nerve root redundancy ${ }^{(\mathbf{8})}$. Min et al. also have found that the group of patients with RNR presented more advanced age, They have not found any statistically significant difference between groups of patient with and without RNR of the cauda equina in relation to symptom duration, and observed a non-statistically significant tendency for better postoperative outcomes in the group of patients without RNR of the cauda equina $^{(12)}$.

The literature is controversial about the implication of the presence of RNR in the indication for decompressive surgery for spinal canal stenosis. Some investigations suggest that such abnormalities of the nerve roots are irreversible, and, therefore, the neurological symptoms are not susceptible to improvement after surgical decompression $^{(\mathbf{8 , 9})}$. Ono et al. have found that cases of RNR of the cauda equina diagnosed by means of MRI were more severe, and that the presence of such change may negatively affect the surgical outcomes ${ }^{(10)}$. In two other studies, the postoperative improvement was not statistically different in patients with and without RNR of the cauda equina $^{(\mathbf{1 2 , 1 3})}$, but in one of those studies a tendency towards worse results for patients with RNR of the cauda equina was identified, similarly to the results reported by Ono et al., as mentioned in the previous para$\operatorname{graph}^{(\mathbf{1 2})}$. Anyway, the complete regression of stenosis symptoms after surgical decompression is rare in patients with typical RNR, and they frequently continue complaining of dysesthesia and paresthesia ${ }^{(\mathbf{1 3})}$.

\section{CONCLUSION}

At MRI, RNR are often associated with degenerative stenosis of the lumbar vertebral canal and therefore the recognition of such entity is important to avoid equivocal diagnosis and mainly false-positive results for arteriovenous malformations. The clinical significance of such abnormality of the cauda equina in the progression of lumbar canal stenosis is still controversial, but there are indications in the literature suggesting that its identification at MRI may indicate a tendency towards worse postoperative results. Therefore the authors of the present review suggest that radiologists should look for RNR of the cauda equina at MRI and, if applicable, describe such finding in their reports.

\section{REFERENCES}

1. Cressman MR, Pawl RP. Serpentine myelographic defect caused by a redundant nerve root. Case report. J Neurosurg. 1968;28:391-3.

2. Fox JL. Redundant nerve roots in the cauda equina. Case report. J Neurosurg. 1969;30:74-5.

3. Ehni G, Moiel RH, Bragg TG. The "redundant" or "knotted" nerve root: a clue to spondylotic cauda equina radiculopathy. Case report. J Neurosurg. 1970;32:252-4

4. Gulati DR, Rout D. Myelographic block caused by redundant lumbar nerve root. Case report. J Neurosurg. 1973;38:504-5. 
5. Duncan AW, Kido DK. Serpentine cauda equina nerve roots. Radiology. 1981;139:109-11.

6. de Tribolet N, Campiche R. Redundant nerve roots of the cauda equina. A rare disease? Eur Neurol. 1982;21:169-74.

7. Hacker DA, Latchaw RE, Yock DH Jr, et al. Redundant lumbar nerve root syndrome: myelographic features. Radiology. 1982;143:457-61.

8. Suzuki K, Ishida Y, Ohmori K, et al. Redundant nerve roots of the cauda equina: clinical aspects and consideration of pathogenesis. Neurosurgery. 1989;24:521-8.

9. Suzuki K, Takatsu T, Inoue H, et al. Redundant nerve roots of the cauda equina caused by lumbar spinal canal stenosis. Spine. 1992;17:133742.

10. Ono A, Suetsuna F, Irie T, et al. Clinical significance of the redundant nerve roots of the cauda equina documented on magnetic resonance im- aging. J Neurosurg Spine. 2007;7:27-32.

11. Hakan T, Celikoğlu E, Aydoseli A, et al. The redundant nerve root syndrome of the cauda equina. Turk Neurosurg. 2008;18:204-6.

12. Min JH, Jang JS, Lee SH. Clinical significance of redundant nerve roots of the cauda equina in lumbar spinal stenosis. Clin Neurol Neurosurg. 2008;110:14-8.

13. Tsuji $\mathrm{H}$, Tamaki $\mathrm{T}$, Itoh $\mathrm{T}$, et al. Redundant nerve roots in patients with degenerative lumbar spinal stenosis. Spine. 1985;10:72-82.

14. Verbiest H. A radicular syndrome from developmental narrowing of the lumbar vertebral canal. J Bone Joint Surg Br. 1954;36-B:230-7.

15. Verbiest H. Sur certaines formes rares de compression de la queue de cheval. In: Hommage à Clovis Vincent. Paris: Maloine; 1949. p. 161-74.

16. Renstein L, Twardzik FG, Russo GL, et al. Electromyographic abnormalities in redundant nerve root syndrome of the cauda equina. Arch Phys Med Rehabil. 1984;65:270-2.

17. Gilbertson JR, Miller GM, Goldman MS, et al Spinal dural arteriovenous fistulas: MR and myelographic findings. AJNR Am J Neuroradiol. 1995;16:2049-57.

18. Friedrich H, Gilsbach J, Mennel HD, et al. Knotted neurinoma or plexiform neurofibroma in the cauda equina (author's transl). Neurochirurgia (Stuttg). 1978;21:135-8.

19. Rengachary SS, McGregor DH, Watanabe I, et al Suggested pathological basis of "redundant nerve root syndrome" of the cauda equina. Neurosurgery. 1980;7:400-11.

20. Pau A, Orunesu G, Sehrbundt Viale E, et al. Mobile neurinoma of the cauda equina. Case report. Acta Neurochir (Wien). 1982;60:115-7. 